\title{
Possible side effects of sugar supplementary nutrition on honey bee health
}

\author{
Davide Frizzera ${ }^{1}$, Simone Del FabBro ${ }^{1}$, Giacomo Ortis ${ }^{2}$, Virginia ZanNi ${ }^{1}$, \\ Renzo BortolomeazzI ${ }^{1}$, Francesco NazzI ${ }^{1}$, Desiderato AnNoscia ${ }^{1}$ \\ ${ }^{1}$ Dipartimento di Scienze AgroAlimentari, Ambientali e Animali, University of Udine, Via delle Scienze n. 206, 33100, \\ Udine (UD), Italy \\ ${ }^{2}$ Dipartimento di Agronomia Animali Alimenti Risorse Naturali e Ambiente-DAFNAE, University of Padova, Padua, \\ Italy
}

Received 30 July 2019 - Revised 8 January 2020 - Accepted 22 January 2020

\begin{abstract}
Food shortage, along with biotic stressors, contributes to winter honey bee colony losses. In autumn, to support honey bee colonies and prepare them for the winter season, beekeepers can supply homemade syrups which could contain compounds with possible negative side effects. In this study, we investigated the toxicity of one of those compounds (e.g., hydroxymethylfurfural, HMF) at doses consistent with literature data both to healthy bees and bees challenged with their most important parasite (i.e., Varroa destructor). To strengthen available data on HMF concentration in sugar syrups, we also investigated HMF formation in homemade 2:1 inverted sugar syrup, considering, in particular, the influence of temperature or boiling time on different homemade sugar syrups according to their acidity. Finally, we studied the effects of the acidity of sugar syrups on honeybee survival, and tested whether or not sucrose inversion through acidification is really necessary. We show that doses of HMF similar to those reported as sublethal in the literature appear to be non-toxic even to mite infested bees. However, the amount of HMF that can be found in homemade syrups, which increases with temperature and acidity, can be much higher and can cause significant bee mortality. Moreover, we highlighted the detrimental effect of syrups acidity on honeybee survival, suggesting that the addition of lemon or any other acidifying substance to invert the sucrose could be harmful and not necessary. Our results suggest a responsible approach to homemade colony nutrition.
\end{abstract}

\section{honey bee / hydroxymethylfurfural / nutrition / sugar syrup acidity}

\section{INTRODUCTION}

Nutrition plays a fundamental role in maintaining strong and healthy honey bee colonies. Honey bees use carbohydrates to obtain energy, proteins for growth and development, and lipids for energy reserves, whereas minerals, vitamins, and water

Electronic supplementary material The online version of this article (https://doi.org/10.1007/s13592-020-00745-6) contains supplementary material, which is available to authorized users.

Corresponding author: D. Annoscia, desiderato.annoscia@uniud.it

Manuscript editor: Cedric Alaux are needed for optimal survival (Standifer et al. 1977). Honey bees gather these substances by collecting nectar, pollen, and water from the natural environment. However, in some periods of the year and in some areas, natural resources can be limited and not match the colony's needs. For this reason, beekeepers normally sustain colonies with additional sources of carbohydrates (Haydak 1970; Brodschneider and Crailsheim 2010; Krainer et al. 2016), using homemade inverted sugar syrups, high fructose corn syrup (HFCS), or starch syrup (Jachimowicz and El Sherbiny 1975; LeBlanc et al. 2009; Brodschneider and Crailsheim 2010; Brodschneider et al. 2010; Krainer et al. 2016). Additional sources of 
proteins, consisting of pollen supplements or pollen substitutes (Standifer et al. 1977), can also be provided. Carbohydrate-rich supplementary food provides an alternative source of energy, increases colony strength, prevents starvation, and may reduce wintering losses (Emsen and Dodologlu 2014). A mixture of sucrose and water is commonly used to feed honey bee colonies that do not have sufficient stores to survive during winter (Free and Spencer-Booth 1961; Barker 1971; Semkiw and Skubida 2016); in fact, in temperate areas, supplementary feeding usually occurs in the autumn period, when honey bees may suffer from low nectar flow and bad weather conditions. The most common diet for supplementary feeding consists in inverted sugar syrup obtained by mixing sugar and water in a 2:1 ratio to which a variable amount of an acidifying agent is added (Bailey 1966; Standifer et al. 1977; Genc and Aksoy 1993); very often, beekeepers produce this food themselves, boiling a water sugar solution acidified with vinegar or lemon juice.

In temperate climates, winter colony losses caused by a number of interacting stress factors, particularly the parasite Varroa destructor and the associated pathogenic deformed wing virus (DWV), are common (Genersch et al. 2010; Nazzi et al. 2012). To reduce the negative impact of stressors, the supplementary nutrition of bee colonies, which can include both carbohydrates and proteins, has eventually become a standard practice, especially in the autumn period. In fact, several lines of evidence suggest that the capacity of the colony to face both biotic (e.g., parasites and pathogens) and abiotic (e.g., low temperature) stressors can be enhanced by maintaining high colony strength through a convenient supply of pollen and carbohydrates respectively (Haydak 1970; Michener 2007; Annoscia et al. 2017). In general, these recent advancements fit well within an integrated concept of colony health, including both the potential stressors the bee colony must cope with and the available resources (Nazzi and Pennacchio 2014).

However, a responsible approach to bee health requires that also the possible detrimental side effects of any intervention, including supplementary nutrition, are investigated. This issue was considered for some types of sugar syrup as HFCS, starch syrups and inverted sugar syrup and sugar candy
(Barker and Lehner 1978; Rinderer and Baxter 1980; Severson and Erickson 1984; Von der Ohe and Schönberger 2002; Ceksteryte and Racys 2006; LeBlanc et al. 2009; Sammataro and Weiss 2013; Smodiš Škerl and Gregorc 2014; Semkiw and Skubida 2016). However, despite the use of 2:1 sucrose-water sugar syrup is very common (Bailey 1966; Standifer et al. 1977; Genc and Aksoy 1993), only limited scientific information is available on its possible side effects. In fact, to our knowledge, only Bailey (1966) and Jachimowicz and El Sherbiny (1975) thoroughly studied the possible side effects of a supplementary sugar nutrition based on inverted 2:1 sucrosewater solutions. In particular, Bailey found that 2:1 acid-hydrolysed carbohydrates are toxic to bees but their mode of action remained rather obscure. Moreover, Bailey excluded the possibility that hydroxymethylfurfural (HMF) and/or its degradation compounds (i.e., laevulinic acid and formic acid), at the concentration found in syrups (0.04 $0.2 \%$ ) could be the cause of the recorded toxicity. $\mathrm{HMF}$ is an organic compound consisting of a furan ring containing both an aldehyde and an alcohol function, which has been proved to be harmful to adult bees at 150 ppm (Jachimowicz and El Sherbiny 1975) and 8000 ppm in sugar solution (Krainer et al. 2016), 250 ppm in HFCS syrup (LeBlanc et al. 2009), and 915 ppm in sugar candies (Smodiš Škerl and Gregorc 2014), while negative effects on larvae were observed at concentrations higher than $750 \mathrm{ppm}$ (Krainer et al. 2016). This compound can be formed both through the Maillard reaction and the thermal and acidcatalyzed degradation of sugars and carbohydrates (Zirbes et al. 2013; Krainer et al. 2016). Thus, HMF can be found in many foods and, in particular, HMF in honey represents a qualitydetermination compound (Spano et al. 2008); indeed, HMF is normally absent in fresh honey but concentration increases with time, storage methods, and excessive heat (Tomasini et al. 2012). Nevertheless, HMF toxicity risk in sugar syrup is still debated and unclear (Zirbes et al. 2013). Indeed, Zirbes et al. (2013) states that it is currently impossible to establish a maximal concentration limit for HMF in relation to honey bee health and standardized experiments are currently lacking. 
To further contribute to understanding the real harmfulness of HMF, we investigated the toxicity of HMF at doses consistent with literature data (Jachimowicz and El Sherbiny 1975; LeBlanc et al. 2009; Krainer et al. 2016) both in healthy bees and bees challenged with their most important parasite (i.e., $V$. destructor). To strengthen available data on HMF concentration in sugar syrups, we also investigated HMF formation in homemade 2:1 inverted sugar syrup, considering, in particular, the influence of temperature or boiling time on different homemade sugar syrups according to their acidity. Finally, we fed honey bees with these syrups to disentangle the role of various factors (e.g., HMF, acidity, other possible compounds) on honey bees survival.

\section{MATERIALS AND METHODS}

\subsection{Honey bees and Varroa mites used in this study}

Experiments were carried out between May 2016 and September 2018. Newly emerged adult bees and mites were collected randomly from several colonies of the experimental apiary of the Dipartimento di Scienze AgroAlimentari, Ambientali e Animali of the University of Udine (46 04' 53.3" N, $13^{\circ} 1233.1$ " E). Previous studies indicated that local honey bee colonies are hybrids between Apis mellifera ligustica Spinola and Apis mellifera carnica Pollmann (Comparini and Biasiolo 1991).

\subsection{Homemade syrups preparation}

Homemade syrups were prepared according to a standard recipe which suggests to add the juice obtained from a lemon to a 2:1 sucrose/water solution obtained by dissolving $1800 \mathrm{~g}$ of sucrose (brand "Maxi," 100\% sucrose) in $900 \mathrm{~mL}$ of water (brand "Sant'Anna," dry residue $22 \mathrm{mg} / \mathrm{L}$, water hardness $0.9^{\circ} \mathrm{F}$ ) and then to stir the mixture while heating. Since heating time differs from one recipe to another, with some suggesting to boil the solution for up to $30 \mathrm{~min}$, we prepared our homemade syrups at three different temperatures $\left(25^{\circ} \mathrm{C}\right.$, $50{ }^{\circ} \mathrm{C}$, and $110^{\circ} \mathrm{C}$; in this latter case, the solution was left to boil for $10 \mathrm{~min}$ ).
To assess the role of lemon juice, two groups of solutions were created: in one group, we added a dose of lemon, corresponding to $1 / 10$ of ten squeezed lemons (variety Femminello, organic), while the other group received no lemon.

The concentration of HMF was quantified using a reflectometer (Reflectometer RQflex®plus Reflectoquant $\left.{ }^{\circledR}\right)$ (Hoštélková et al. 2013; Vrzal et al. 2019) 1 day after the preparation of homemade syrups since the compound needs about $24 \mathrm{~h}$ to reach a stable concentration. Three technical replicates were made for each sample. $\mathrm{pH}$ was assessed at room temperature $\left(20^{\circ} \mathrm{C}\right)$ using a pHmeter (XS 8 series, resolution $\pm 0.1 / 0.01 \mathrm{pH})$. The experiment was replicated three times.

\subsection{Effects of homemade syrups on the survival of honey bees}

To investigate the possible side effects of wintering supplementary food on the survival of bees, we fed honey bees with homemade syrups produced in the previous experiment (Section 2.2).

To this aim, the day before the experiment, several combs containing emerging bees were randomly collected from the apiary and stored overnight in a climatic chamber $\left(34.5^{\circ} \mathrm{C}, 75 \%\right.$ R.H., dark). The day after, groups of 23 to 27 newly emerged honey bees were transferred into plastic cages $(185 \times 105 \times 85 \mathrm{~mm})$ and maintained under the same controlled conditions; each cage was set up making sure that the same number of bees from the same comb was present in each cage. Bees were fed ad libitum with water and the homemade syrups, which consisted in: 2:1 sucrose solution produced at $25{ }^{\circ} \mathrm{C}$ (labeled as $\mathrm{L}-25{ }^{\circ} \mathrm{C}$ in figures), 2:1 sucrose solution with lemon produced at $25{ }^{\circ} \mathrm{C}\left(\mathrm{L}+25^{\circ} \mathrm{C}\right)$, sucrose solution, boiled for $10 \mathrm{~min}$ at $110{ }^{\circ} \mathrm{C}$ (L-boiled), sucrose solution with lemon, boiled for $10 \mathrm{~min}$ at $110{ }^{\circ} \mathrm{C}(\mathrm{L}+$ boiled $), 2: 1$ sucrose solution with lemon and $\mathrm{HMF}\left(\mathrm{L}+25^{\circ} \mathrm{C} \mathrm{HMF}\right)$, and 2:1 sucrose solution with HMF (L-25 $\left.{ }^{\circ} \mathrm{C} \mathrm{HMF}\right)$. The concentration of HMF in $\mathrm{L}+25^{\circ} \mathrm{C} \mathrm{HMF}$ and $\mathrm{L}-25^{\circ} \mathrm{C}$ $\mathrm{HMF}$ corresponded to the concentration of HMF found in the sucrose solution added with lemon and boiled for $10 \mathrm{~min}$ at $110{ }^{\circ} \mathrm{C}(\mathrm{L}+$ boiled). The concentration of HMF was $95 \mathrm{mg} / \mathrm{L}, 83 \mathrm{mg} / \mathrm{L}$, 
and $77 \mathrm{mg} / \mathrm{L}$ in the three replicates of the experiment, respectively.

To assess the composition of the feeding solutions as altered by the thermal treatment, an aliquot of the $\mathrm{L}+$ boiled syrup and L-25 ${ }^{\circ} \mathrm{C}$ syrup were analyzed by high-performance liquid chromatography (HPLC). For this purpose, $1 \mathrm{~g}$ of syrup was diluted with $4 \mathrm{~mL}$ of water and loaded on a 1-g Strata C18-E Solid Phase Extraction (SPE) column (Phenomenex, Italy) previously conditioned with $5 \mathrm{~mL}$ of methanol and $5 \mathrm{~mL}$ of water. After loading, the column was washed with $3 \mathrm{~mL}$ of water and the less polar compounds were then eluted with $4 \mathrm{~mL}$ of methanol. The volume of the methanolic fraction was reduced to about $0.5 \mathrm{~mL}$ under a nitrogen stream and the sample was then transferred to an autosampler vial for the HPLC-UV analysis.

An UHPLC Shimadzu Nexera R (Shimadzu, Milan, Italy) coupled to a SPD-M20A Photo Diode Array detector and equipped with a degasser, a thermostated autosampler, and a column oven was used. The chromatographic separation was performed with an Agilent Poroshell 120 EC$\mathrm{C} 18,4.6 \times 150 \mathrm{~mm}, 2.7 \mu \mathrm{m}$ particle size, column (Agilent Technologies, Italy), thermostated at $30{ }^{\circ} \mathrm{C}$. Elution was carried out at a flow rate of $0.45 \mathrm{~mL} \mathrm{~min}^{-1}$, using as mobile phase a mixture of water (solvent A) and acetonitrile (solvent B) with the following gradient: 0-2 min, isocratic condition at 5\% B; 2-30 min, linear gradient from 2 to $95 \% \mathrm{~B}$. The injection volume was $5 \mu \mathrm{L}$. HMF was identified on the basis of the retention time and UV spectrum of a standard HMF solution.

\subsection{Effects of syrup acidity on the survival of honey bees}

To confirm the effects of acidity on honey bee survival, newly emerged honey bees collected and reared with the same protocol used in previous experiments ( $n=30$ per cage) were fed ad libitum with three different solutions: 2:1 sucrose solution produced at $25{ }^{\circ} \mathrm{C}$ (labeled as L- $25{ }^{\circ} \mathrm{C}$ in figures), 2:1 sucrose solution produced at $25{ }^{\circ} \mathrm{C}$ with lemon $\left(\mathrm{L}+25^{\circ} \mathrm{C}\right)$, and $2: 1$ sucrose solution produced at $25{ }^{\circ} \mathrm{C}$ and acidified with $\mathrm{HCl}(\mathrm{HCl}$ $\left.25^{\circ} \mathrm{C}\right)$.
The homemade syrup solutions used here were the same as those used before, except $\mathrm{HCl} 25^{\circ} \mathrm{C}$ solution that was originally an aliquot of $\mathrm{L}-25^{\circ} \mathrm{C}$ acidified with $\mathrm{HCl}$ to reach the same $\mathrm{pH}$ of $\mathrm{L}+25^{\circ} \mathrm{C}(\mathrm{pH}=2.80)$.

Three replicates using three different cages were made (each replicate corresponded to one cage).

Acidity of food stuff may interfere with the integrity of the epithelium of the intestinal tract and disrupt the abundance and composition of the gut microbiota (Ptaszynska et al. 2013); such effect may be difficult to measure, but may be indirectly assessed based on the response of genes that are regarded as suitable marker of nutritional stress, immune genes, and the abundance of widespread bee pathogens. Therefore, to further investigate any possible side effect of acidity on honey bees, we performed a quantitative real-time PCR (qRT-PCR) assessing the relative expression of vitellogenin and apidaecin, together with the deformed wing virus (DWV) relative load.

Vitellogenin was selected as a marker of nutritional and biotic stress (Amdam et al. 2011; Dainat et al. 2012a; Dolezal et al. 2016; Smart et al. 2016; Zanni et al. 2017); the antimicrobial peptide apidaecin was used to investigate the possible effects on honey bees' immune-competence, while DWV was studied since it represents a constant pathogenic threat for honey bees (Nazzi and Pennacchio 2018). A total of 6 bees for each experimental group were used for analysis; three technical replicates were performed for each sample.

RNA extractions were performed with Rneasy® Plus Mini Kit (Qiagen), cDNA synthesis with Moloney Murine Leukemia Virus Reverse Transcriptase (M-MLV RT, Promega) and real-time PCR using the CFX96 ${ }^{\mathrm{TM}}$ optical reaction module (Bio-Rad) and the C1000 Touch ${ }^{\mathrm{TM}}$ thermal cycler (Bio-Rad). $\beta$-Actin and GAPDH were used as housekeeping genes. Primer pairs adopted in this study are reported in Supplementary Material (SM_Table I).

\subsection{Toxicity of low HMF doses on healthy and mite infested bees}

To assess the possible negative effects of HMF in homemade wintering food, we investigated the survival of uninfested and mite infested honey 
bees at doses similar to those developed in our homemade syrups and also compatible with those reported in literature.

For this purpose, sealed brood combs from several colonies of the apiary were transferred into the lab and stored in a net cage to collect emerging bees as they eclosed from brood cells; then, newly emerged bees were transferred into plastic cages $(185 \times 105 \times 85 \mathrm{~mm})$ and maintained in a climatic chamber $\left(34.5{ }^{\circ} \mathrm{C}, 75 \%\right.$ R.H., dark). Bees ( $n=25$ per cage) were fed ad libitum with water and different diets. Diet consisted in a sugar solution (glucose 61\%, fructose 39\%; Thom et al. 2003) added with $0,50,100,200$, and $400 \mathrm{mg} / \mathrm{L}$ of HMF. The bee mortality was recorded daily. The experiment was replicated twice. A total of fifty bees per group were used.

Since the experiments revealed no negative effect of these doses of HMF on uninfested bees, the toxicity of HMF to mite infested honey bees was studied using the highest dose tested on healthy bees $(400 \mathrm{mg} / \mathrm{L})$. To do so, we collected mature bee larvae from brood cells capped in the preceding $15 \mathrm{~h}$ and transferred them into gelatin capsules (Agar Scientific Ltd., $6.5 \mathrm{~mm} \varnothing$ ) with no mites $(\mathrm{V}-)$ or one mite $(\mathrm{V}+)$ that had been collected from recently sealed brood cells (Nazzi and Milani 1994; Nazzi et al. 2012); bees were maintained in an environmental chamber at $34.5{ }^{\circ} \mathrm{C}, 75 \%$ R.H., dark, for 12 days. Upon eclosion, newly emerged adult bees were separated from the infesting mite and transferred into plastic cages $(185 \times 105 \times$ $85 \mathrm{~mm}$ ), maintained in a climatic chamber at $34.5^{\circ} \mathrm{C}, 75 \%$ R.H., dark; bees developing in cells where the mite was dead were not considered since, in this case, an effective mite infestation could not be taken for granted. Bees ( $n=30-40$ per cage) were fed ad libitum with water and sugar solution (0 mg/L HMF) or sugar solution (glucose $61 \%$, fructose 39\%) with $400 \mathrm{mg} / \mathrm{L}$ of HMF (400 mg/L HMF). The experiment was replicated twice. From 62 up to 80 honey bees for each experimental group were used in total.

\subsection{HMF concentration in relation to $\mathrm{pH}$ and boiling time}

Since our experiments showed that HMF concentration is enhanced in sugar syrups acidified with lemon and boiled for $10 \mathrm{~min}$, we carried out another experiment to better study the HMF formation in relation to $\mathrm{pH}$ and boiling time.

To this aim, three sucrose syrups acidified with $\mathrm{HCl}$ at 2, 3, and $4 \mathrm{pH}$ were boiled for $40 \mathrm{~min}$ at $110{ }^{\circ} \mathrm{C}$. To follow HMF formation, every $10 \mathrm{~min}$, from the beginning of boiling till $40 \mathrm{~min}$ after, $20 \mathrm{~mL}$ of each syrup was sampled to assess HMF concentration as described above.

\subsection{Effects of high HMF doses on honey bees}

To investigate the effect on honey bees of high HMF doses that could develop at low $\mathrm{pH}$ and prolonged boiling time, we studied the survival of caged honey bees fed with $10,000 \mathrm{mg} / \mathrm{L}$ of HMF in sugar syrup. This concentration was selected based on the experiment described before which showed that up to $6000-14,000 \mathrm{ppm}$ of HMF are formed in sugar syrup after 30 and $40 \mathrm{~min}$ of boiling, respectively. Indeed, many beekeeper recipes suggest to boil syrups for $30 \mathrm{~min}$ or more. Moreover, this dose is comparable to that used by Krainer et al. (2016) in their experiments.

For the purpose, 30 bees per experimental group were fed ad libitum with two different solutions: 2:1 sucrose solution produced at $25^{\circ} \mathrm{C}$ (labeled as sucrose in figures) and 2:1 sucrose solution produced at $25{ }^{\circ} \mathrm{C}$ added with $10,000 \mathrm{mg} / \mathrm{L}$ of HMF (HMF 10000). This experiment was replicated three times.

\subsection{Effects of different monosaccharides on honey bees}

To verify the need to invert sucrose in homemade syrups and thus the importance of lemon juice addition, we studied the survival of bees fed either with monosaccharide or disaccharide sugars at $\mathrm{pH}=7$. We therefore reared in plastic cages newly emerged honey bees $(n=30$ per cage) obtained as above and provided either a water and a sucrose solution ad libitum (labeled as sucrose in figures) or a 1:1:1 water, glucose, and fructose solution (glucose and fructose). Three replicates with three different cages were made 
for this experiment (each replicate corresponded to one cage).

\subsection{Statistical analysis}

All statistics analysis were performend with Minitab 16®. Each survival curve was compared with its control using the log-rank test. Since in the experiment "Effects of homemade syrups on honey bees" several groups were compared, we applied a correction according to Benjamini and Hochberg (1995), setting the false discovery rate at 0.1 .

\section{RESULTS}

\subsection{Acidity and HMF concentration of sugar syrups}

In the first replicate of the experiment, 10 squeezed lemons produced $490 \mathrm{~mL}$ of lemon juice, whereas in the second and third replication, 337 and $311 \mathrm{~mL}$ were produced, respectively. Since we used $1 / 10$ of the squeezable juice, $49,33.7$, and $31.1 \mathrm{~mL}$ of lemon juice were added respectively to the sugar solution in each replicate, reaching a $\mathrm{pH}$ ranging from 2.87 and 2.96 (Table I). However, it is worth noting that, in previous preliminary experiments, a $\mathrm{pH}$ as low as 1.65 in one case

Table I. $\mathrm{pH}$ of homemade sugar solutions according to the preparation method: temperature and presence or absence of lemon (L+ and L-, respectively)

\begin{tabular}{lllll}
\hline & & $25{ }^{\circ} \mathrm{C}$ & $50{ }^{\circ} \mathrm{C}$ & $\begin{array}{l}110{ }^{\circ} \mathrm{C} \\
\text { boiled 10' }\end{array}$ \\
\hline 1st replicate & L- & 7.37 & 7.13 & 8.23 \\
& L+ & 2.96 & 2.97 & 3.00 \\
2nd replicate & L- & 7.32 & 7.08 & 7.06 \\
& L+ & 2.87 & 2.9 & 2.84 \\
3rd replicate & L- & 6.05 & 7.01 & 6.30 \\
& L+ & 2.87 & 2.75 & 2.88 \\
Mean & L- & 6.91 & 7.07 & 7.20 \\
Std-dev. & & 0.75 & 0.06 & 0.97 \\
Mean & L+ & 2.90 & 2.87 & 2.91 \\
Std-dev. & & 0.05 & 0.11 & 0.08 \\
& & & & \\
\hline
\end{tabular}

and 2.61 in another case was obtained, using the same lemon variety and procedure; therefore, it is safe to conclude that the addition of one lemon to $1 \mathrm{~L}$ of a sugar solution can reduce the $\mathrm{pH}$ to 2 or even less.

The combination of acidity and heating affects HMF formation but only when high temperatures are applied (Table II); in fact, acidified sugars syrups, boiled for $10 \mathrm{~min}$, reached an average HMF concentration of $85 \pm 9.17 \mathrm{mg} / \mathrm{L}$ (the high standard deviation could be partly related to the accuracy of the reflectometer $( \pm 2.5))$. The HLPC analysis (Fig. 1) confirmed the presence of high concentrations of HMF in the acidified-boiled sucrose solution $(\mathrm{L}+$ boiled $)$; other minor peaks were observed as well in this solution that were absent from the sucrose solution produced at $25^{\circ} \mathrm{C}\left(\mathrm{L}-25^{\circ} \mathrm{C}\right)$.

\subsection{Effects of homemade syrups on the survival of honey bees}

According to their survival, the bees that received the various treatments could be grouped as follows. The highest survival was observed in bees fed with sugar syrup to which no lemon was added, regardless of heating (L-25 ${ }^{\circ} \mathrm{C}$, L-boiled, L-25 ${ }^{\circ} \mathrm{C}$ HMF; Fig. 2). In

Table II. HMF (mg/L) produced in homemade sugar solutions according to the preparation method: temperature and presence or absence of lemon ( $\mathrm{L}+$ and L-, respectively)

\begin{tabular}{lccll}
\hline & & $25{ }^{\circ} \mathrm{C}$ & $50{ }^{\circ} \mathrm{C}$ & $\begin{array}{l}110{ }^{\circ} \mathrm{C} \\
\text { boiled 10 }\end{array}$ \\
\hline 1st replicate & L- & 2.3 & 2.8 & 3.8 \\
& L+ & 3.1 & 2.6 & 95.0 \\
2nd replicate & L- & 2.8 & 3.3 & 1.6 \\
& L+ & 1.6 & 3.0 & 83.0 \\
3rd replicate & L- & 1.8 & 2.2 & 1.5 \\
& L+ & 2.4 & 2.8 & 77.0 \\
Mean & L- & 2.3 & 2.8 & 2.3 \\
Std-dev. & & 0.5 & 0.6 & 1.3 \\
Mean & L+ & 2.4 & 2.8 & 85.0 \\
Std-dev. & & 0.7 & 0.2 & 9.2 \\
& & & & \\
\hline
\end{tabular}




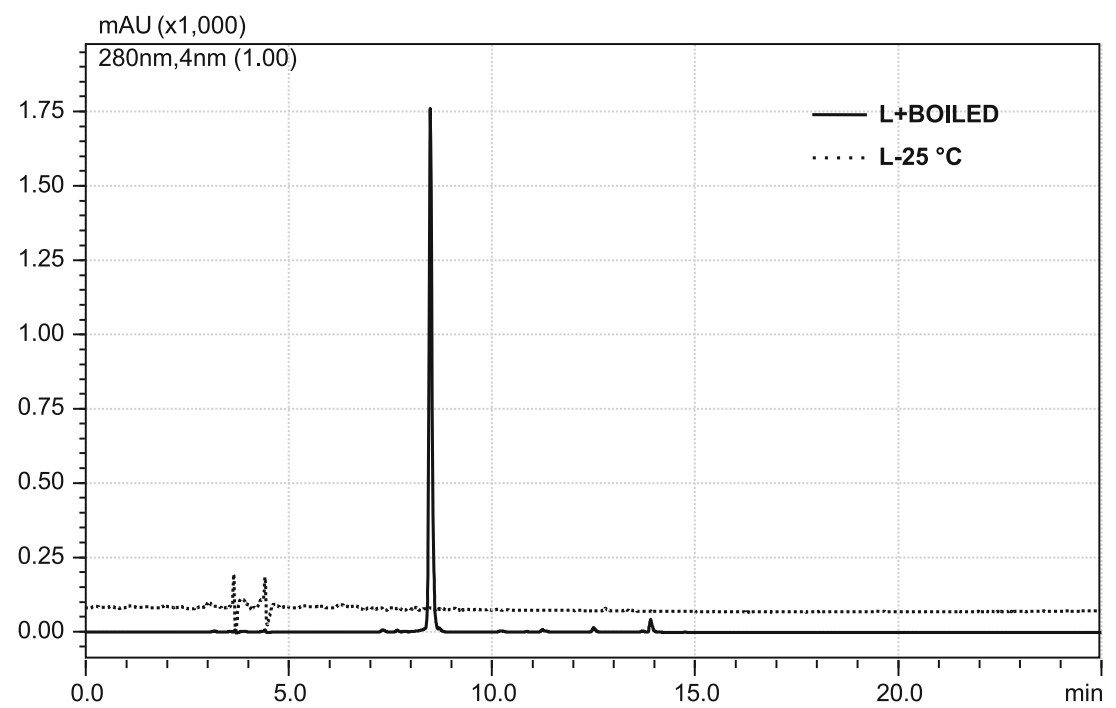

Figure 1. HPLC analysis of an acidified-boiled sugar solution $\left(\mathrm{L}+\right.$ boiled) and a sugar solution produced at $25^{\circ} \mathrm{C}$ without lemon $\left(\mathrm{L}-25^{\circ} \mathrm{C}\right)$.

this group, no significant differences were found among the three treatments, and, in particular, between L-25 ${ }^{\circ} \mathrm{C}$ and L-25 ${ }^{\circ} \mathrm{C}$ HMF (Table III, comparisons n. 1, 2, 3).

An intermediate survival was observed in bees fed with acidified but not boiled sugar syrup $\left(\mathrm{L}+25{ }^{\circ} \mathrm{C}, \mathrm{L}+25{ }^{\circ} \mathrm{C} \mathrm{HMF}\right.$; Fig. 2); again, the addition of HMF did not affect the survival at this stage (Table III, comparison 4).

Finally, the lowest survival was observed in bees fed with an acidified solution boiled for $10 \min$ (L+boiled, Fig. 2).

The survival of bees belonging to each of three groups was significantly different from that of

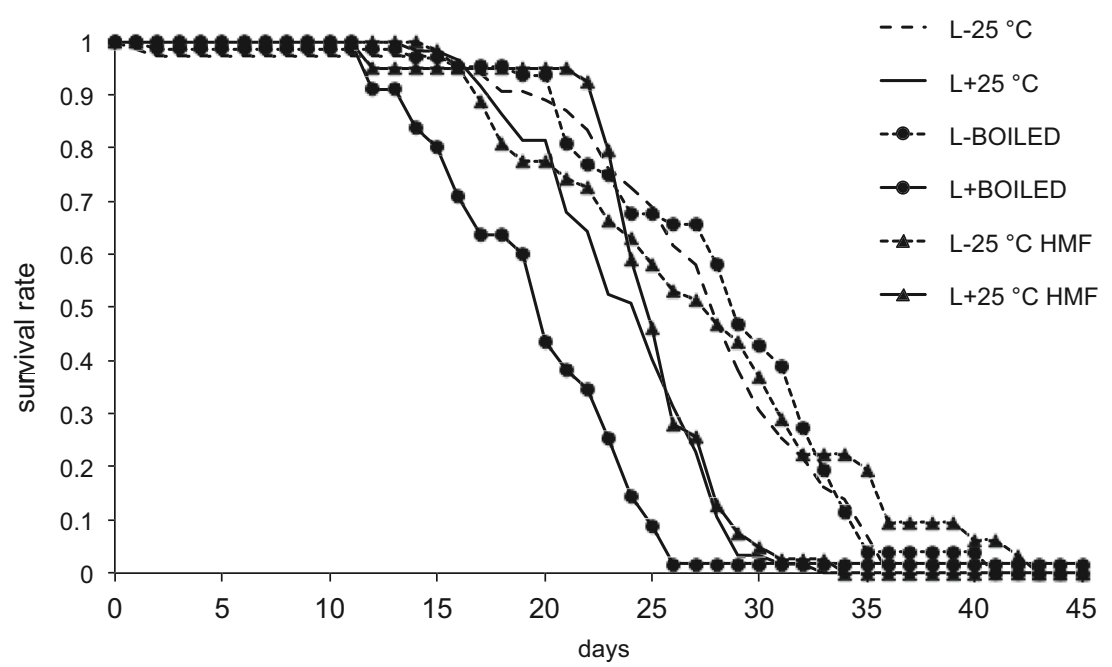

Figure 2. Effects of different sugar syrups on honey bees survival $(n=74-76)$. 
Table III. Statistical analysis (log-rank test) related to the survival of honey bees fed with different sugar syrups (Fig. 2)

\begin{tabular}{|c|c|c|c|c|}
\hline & Comparison & Chi-square & d.f. & $P$ value \\
\hline 1 & $\mathrm{~L}-25{ }^{\circ} \mathrm{C}$ vs. $\mathrm{L}-25{ }^{\circ} \mathrm{C} \mathrm{HMF}$ & 0.56708 & 1 & 0.451 \\
\hline 2 & $\mathrm{~L}-25{ }^{\circ} \mathrm{C}$ vs. L-boiled & 0.57005 & 1 & 0.450 \\
\hline 3 & L-boiled vs. L- $25{ }^{\circ} \mathrm{C}$ HMF & 0.01982 & 1 & 0.888 \\
\hline 4 & $\mathrm{~L}+25^{\circ} \mathrm{C}$ vs. $\mathrm{L}+25^{\circ} \mathrm{C} \mathrm{HMF}$ & 1.35442 & 1 & 0.245 \\
\hline 5 & $\mathrm{~L}+25^{\circ} \mathrm{C}$ vs. $\mathrm{L}-25^{\circ} \mathrm{C}$ & 22.4025 & 1 & $<0.001$ \\
\hline 6 & $\mathrm{~L}+25^{\circ} \mathrm{C}$ vs. $\mathrm{L}-25^{\circ} \mathrm{C} \mathrm{HMF}$ & 17.8190 & 1 & $<0.001$ \\
\hline 7 & $\mathrm{~L}+25^{\circ} \mathrm{C}$ vs. L-boiled & 29.4064 & 1 & $<0.001$ \\
\hline 8 & $\mathrm{~L}+25^{\circ} \mathrm{C}$ vs. $\mathrm{L}+$ boiled & 28.2390 & 1 & $<0.001$ \\
\hline 9 & $\mathrm{~L}+25^{\circ} \mathrm{C}$ HMF vs. $\mathrm{L}-25^{\circ} \mathrm{C}$ & 11.9552 & 1 & 0.001 \\
\hline 10 & $\mathrm{~L}+25^{\circ} \mathrm{C}$ HMF vs. $\mathrm{L}-25^{\circ} \mathrm{C} \mathrm{HMF}$ & 93.9784 & 1 & 0.002 \\
\hline 11 & $\mathrm{~L}+25^{\circ} \mathrm{C}$ HMF vs. L-boiled & 15.5093 & 1 & $<0.001$ \\
\hline 12 & $\mathrm{~L}+25^{\circ} \mathrm{C}$ HMF vs. $\mathrm{L}+$ boiled & 36.2876 & 1 & $<0.001$ \\
\hline 13 & $\mathrm{~L}+$ boiled vs. $\mathrm{L}-25^{\circ} \mathrm{C}$ & 61.1796 & 1 & $<0.001$ \\
\hline 14 & $\mathrm{~L}+$ boiled vs. $\mathrm{L}-25^{\circ} \mathrm{C} \mathrm{HMF}$ & 45.1172 & 1 & $<0.001$ \\
\hline 15 & $\mathrm{~L}+$ boiled vs. L-boiled & 62.7928 & 1 & $<0.001$ \\
\hline
\end{tabular}

bees belonging to the other groups (Table III, comparisons from 5 to 15 ).

\subsection{Effects of syrup acidity on the survival of honey bees}

Since the previous experiment suggested a negative effect of acidity of the sugar syrup on the survival of bees, we tested this effect using both lemon and hydrogen chloride.

Bees fed with a sugar solution acidified to the same $\mathrm{pH}$ (2.80) either with lemon or hydrogen chloride showed a significantly reduced survival as compared to bees fed the same sugar solution without an acidic addition (Fig. 3; L-25 ${ }^{\circ} \mathrm{C}$ vs. $\mathrm{HCl} 25^{\circ} \mathrm{C}$, log-rank (chi-square $=25.059$, d.f. $=$ $1, P<0.001$ ); $\mathrm{L}-25^{\circ} \mathrm{C}$ vs. $\mathrm{L}+25^{\circ} \mathrm{C}$ log-rank (chisquare $=47.852$, d.f. $=1, P<0.001)$ ). No significant difference was found between the survival of bees fed with solutions acidified with lemon or hydrogen chloride (log-rank (chi-square $=1.103$, d.f. $=1, P=0.294)$ ).

qRT-PCR analysis highlighted a significant lower expression of apidaecin in honey bees fed with $\mathrm{HCl}$ added syrup as compared to control bees fed standard syrup (Fig. $4 \mathrm{a} ; \mathrm{L}-25^{\circ} \mathrm{C}$ vs. $\mathrm{HCl}$
$25{ }^{\circ} \mathrm{C}$, Mann Whitney $(\mathrm{n} 1=6 ; \mathrm{n} 2=6 ; \mathrm{U}=4$; $P=0.013)$ ). No significant differences were found in vitellogenin expression between honey bees fed with control syrup and acidified syrups (Fig. $4 \mathrm{~b}$; L-25 ${ }^{\circ} \mathrm{C}$ vs. $\mathrm{L}+25{ }^{\circ} \mathrm{C}$, Mann Whitney (n1 =6; n2 =6; U = 14; $P=0.260) ; \mathrm{L}-25{ }^{\circ} \mathrm{C}$ vs. $\mathrm{HCl} 25{ }^{\circ} \mathrm{C}$, Mann Whitney $(\mathrm{n} 1=6 ; \mathrm{n} 2=6$; $\mathrm{U}=$ $13 ; P=0.212)$ ). No significant differences were found in the relative DWV load between the control syrup and the one acidified with lemon (L-25 ${ }^{\circ} \mathrm{C}$ vs. $\mathrm{L}+25{ }^{\circ} \mathrm{C}$, Mann Whitney $(\mathrm{n} 1=6$; $\mathrm{n} 2=6 ; \mathrm{U}=17 ; P=0.36)$ ) or the one acidified with $\mathrm{HCl}\left(\mathrm{L}-25^{\circ} \mathrm{C}\right.$ vs. $\mathrm{HCl} 25^{\circ} \mathrm{C}$, Mann Whitney $(\mathrm{n} 1=6 ; \mathrm{n} 2=6 ; \mathrm{U}=8 ; P=0.055)$ ).

\subsection{Toxicity of low HMF doses on healthy and mite infested bees}

To confirm the results of the first experiment, showing no apparent effect of the addition of HMF to the toxicity of sugar solutions, we tested if doses similar to those observed in that trial or found in the literature can affect the bees' survival.

No significant differences and no apparent negative effects on the survival of uninfested bees were observed with HMF doses similar to those found in 


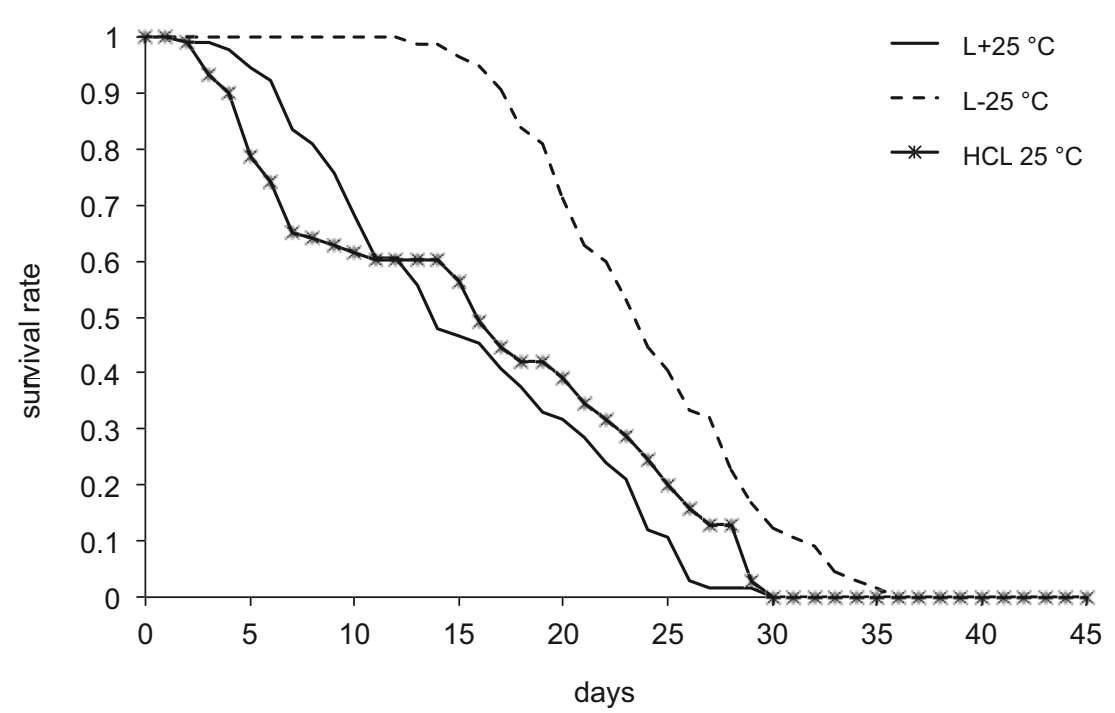

Figure 3. Effects of acidity on honey bees survival $(n=90)$.

our sugar syrups and to those reported in literature (0, 50, 100, 200, $400 \mathrm{mg} / \mathrm{L}$ of HMF) (Fig. 5a).

As expected, bees artificially infested with $V$. destructor showed a reduced lifespan as compared to uninfested bees (V+ $0 \mathrm{mg} / \mathrm{L}$ HMF vs. V$0 \mathrm{mg} / \mathrm{L}$ HMF, log-rank (chi-square $=10.539$, d.f. $=1, P=0.001)$ and $\mathrm{V}-400 \mathrm{mg} / \mathrm{L}$ HMF vs. $\mathrm{V}+400 \mathrm{mg} / \mathrm{L}$ HMF, log-rank (chi-square $=6.001$, d.f. $=1, P=0.014)$ ) (Fig. 5b). Moreover, we observed a notable difference in the shape of the curves between uninfested (Fig. 5a) and mite infested bees (Fig. 5b), with the first group of bees following a type 1 curve and the second following a type 2 survival curve, possibly caused by the different handling of bees during artificial infestation and by the different artificial rearing conditions of immature bees.

In any case, $400 \mathrm{mg} / \mathrm{L}$ of HMF did not negatively affect the survival of bees; actually, an increased survival was observed in infested bees (V+400 mg/ L HMF vs. V+ $0 \mathrm{mg} / \mathrm{L} \mathrm{HMF}$, log-rank (chisquare $=5.052$, d.f. $=1, P=0.025)$ ). This trend was not confirmed in uninfested honey bees were the survival of honey bees treated with $400 \mathrm{mg} / \mathrm{L}$ of HMF was not different from the control (V$400 \mathrm{mg} / \mathrm{L}$ HMF vs. V- $0 \mathrm{mg} / \mathrm{L}$ HMF, log-rank (chi-square $=1.264$, d.f. $=1, P=0.261$ )). These results nicely match the results reported above and obtained in a separate experiment (Fig. 2).

\subsection{HMF concentration in relation to $\mathbf{p H}$ and boiling time}

Considering the results presented above regarding the effect of boiling acidified sugar solutions on HMF formation, and the non-significant effect of low doses of HMF, we wondered if a prolonged heating of acid solutions may result in higher concentration of HMF that could be toxic to bees. To answer this question, we prepared sugar syrups with different acidity $(\mathrm{pH}=2,3,4)$ and assessed HMF formation in relation to increasing boiling time.

We found that boiling time did not strongly affect HMF formation at $\mathrm{pH} 3$ and 4, causing concentrations that, according to our previous results, are non-toxic to bees (i.e., $<3.5 \mathrm{mg} / \mathrm{L}$ ). However, at $\mathrm{pH}=2$, the heating process triggers the formation of a much higher HMF concentrations, ranging from $1786.7 \mathrm{mg} / \mathrm{L}$, after $10 \mathrm{~min}$ of boiling, to $14,366.7 \mathrm{mg} / \mathrm{L} 40 \mathrm{~min}$ later (Fig. 6a).

\subsection{Effects of high HMF doses on the survival of honey bees}

Feeding bees with a sugar syrup containing an HMF concentration similar to that obtained after boiling an acidic solution for a few minutes (i.e., 10,000 mg/L of HMF) caused a 

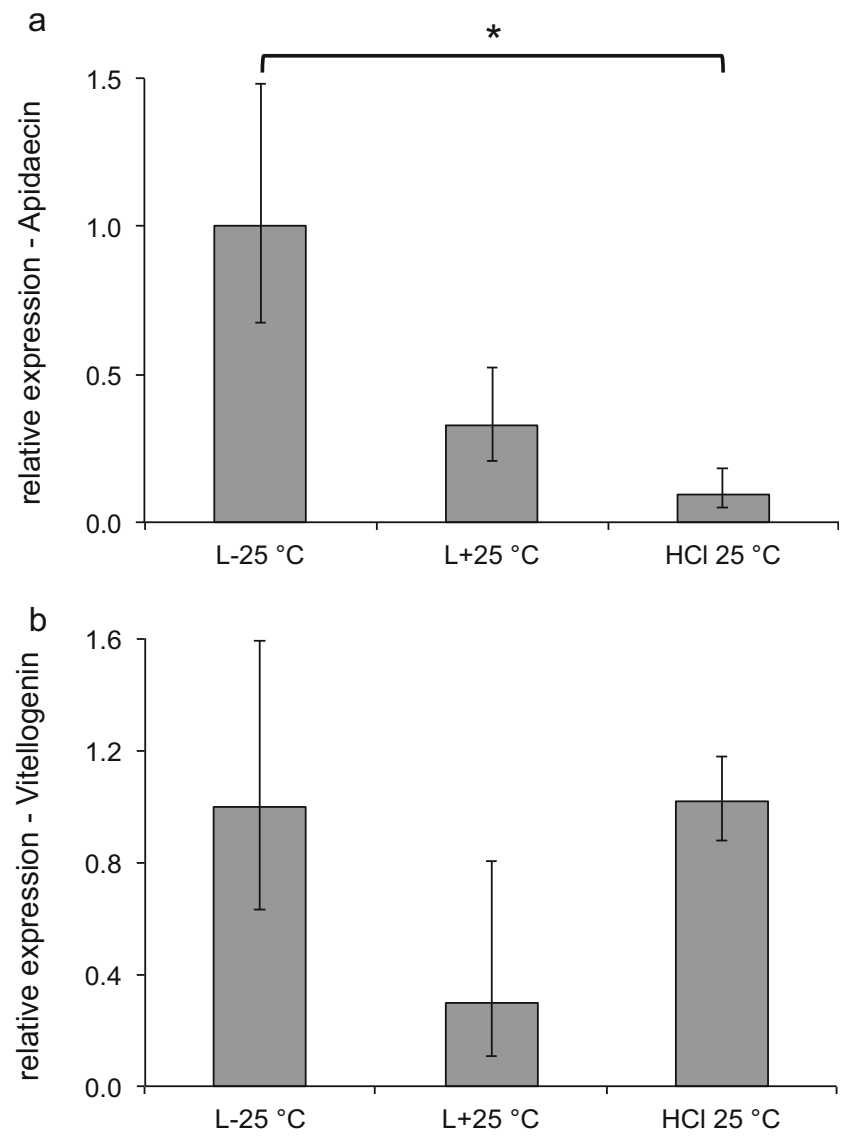

Figure 4. Relative expression of apidaecin (a) and vitellogenin (b) in honey bees treated with different acidified sugar solutions $(n=6)$. A significant difference $(P<0.05)$ between treatments $\left(\mathrm{L}-25^{\circ} \mathrm{C}\right.$ and HCL $\left.25^{\circ} \mathrm{C}\right)$ is marked with an asterisk.

strong significant reduction in the lifespan of bees; indeed, $100 \%$ of mortality was recorded after only 14 days, while more than $85 \%$ of control bees were still alive at the same date (sucrose vs. HMF 10000 , log-rank (chisquare $=16.452$, d.f. $=1, P<0.001)$ (Fig. 6b).

\subsection{Effects of a monosaccharide-based diet on honey bees}

Since acidification of sugar syrups appears to be critical for bee survival, and the purpose of this treatment is to obtain the inversion of disaccharide sugars into monosaccharides, we tested if feeding bees with a sucrose solution instead of glucose and fructose influences their survival.
We found that bees fed with sucrose syrup (the same recipe as that used in previous experiments) had a longer survival than bees fed with a 1:1:1 water, glucose, and fructose solution (sucrose vs. glucose and fructose, log-rank (chi-square $=$ 7.440, d.f. $=1, P=0.006)$ ) (Fig. 7).

\section{DISCUSSION}

Doses of HMF similar to those reported as sublethal in the literature (Jachimowicz and El Sherbiny 1975; LeBlanc et al. 2009) and found in our home made sugar syrups when heating treatment are restricted, seem to be non-toxic both for uninfested and mite infested bees. This result suggests that, at low concentrations, in the range of 10-400 ppm, HMF does not influence bee 

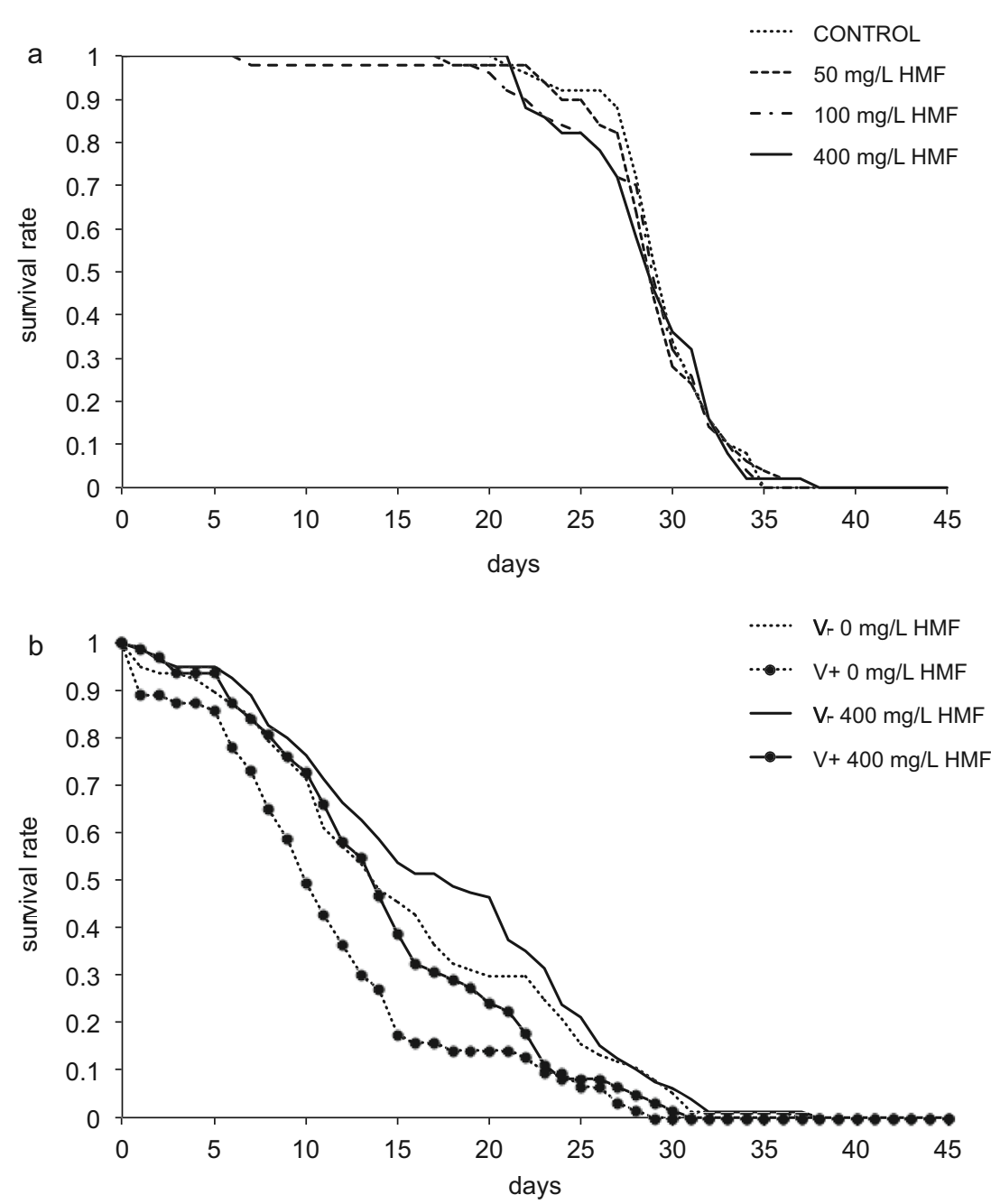

Figure 5. Survival rate of uninfested adult honey bees $(n=50)$ fed with sugar syrup containing different concentrations of HMF (a) and survival rate of adult bees infested $(\mathrm{V}+)$ or not $(\mathrm{V}-)$ with 1 mite during the pupal stage ( $n=62-80$ ) and fed with a sugar syrup containing (or not) $400 \mathrm{mg} / \mathrm{L}$ of HMF (b ).

health, even in presence of the most common additional stressor of bees: the parasite $V$. destructor and the viruses that are normally associated to it.

However, our data show that the lower acidity that can be found in homemade syrups because of lemon addition negatively affects bees' survival, as confirmed by comparing the survival of bees fed a sugar solution acidified or not with lemon. The similar results obtained after changing the acidifying agent support the notion that acidity per se, rather than any toxic compounds from lemon, is responsible for the observed effect. Molecular analysis shows an interesting downregulation of apidaecin in bees fed with $\mathrm{HCl}$ acidified syrups, suggesting an interaction with the bee's immune system. However, we did not find a similar significant pattern in bees fed with lemon, supporting the view that it is not acidity but rather the quality of the acidifying agent that matters in this case.

Vitellogenin expression, which did not differ between groups, suggests that the abiotic stress of acidity may have a limited effect on the gene 

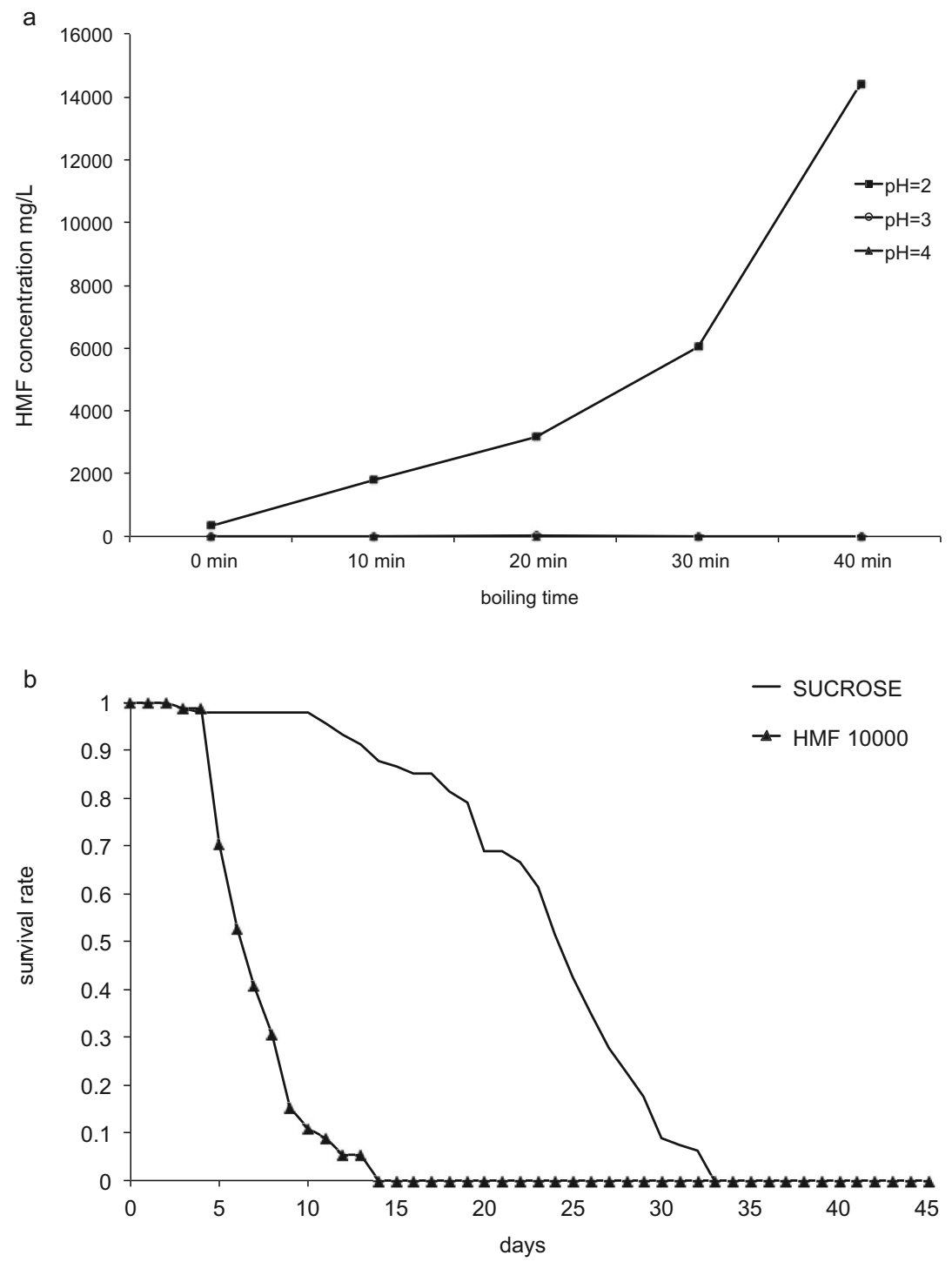

Figure 6. HMF formation in relation to heat treatment and acidity (a); survival rate of honeybees $(n=90)$ fed or not with a very high dose of HMF (b).

expression of this lipoprotein, which, in this case, cannot be regarded as a good marker of stress, differently from a number of other cases (Amdam et al. 2011; Dainat et al. 2012a; Dolezal et al. 2016; Smart et al. 2016; Zanni et al. 2017); however, we cannot rule out that different results may have arisen if bees have had access to pollen during the experiments. The same consideration can be drawn for DWV load, which revealed no differences between the different experimental groups.

Our experiments further showed that acidified sugar solutions may reach much higher concentrations of HMF if a prolonged heating is applied and a low pH level (e.g., $\mathrm{pH}=2$ ) is reached after lemon addition; in fact, both acidity and the amount of lemon juice are influenced by seasonality, climate, and the stage of ripeness of the 


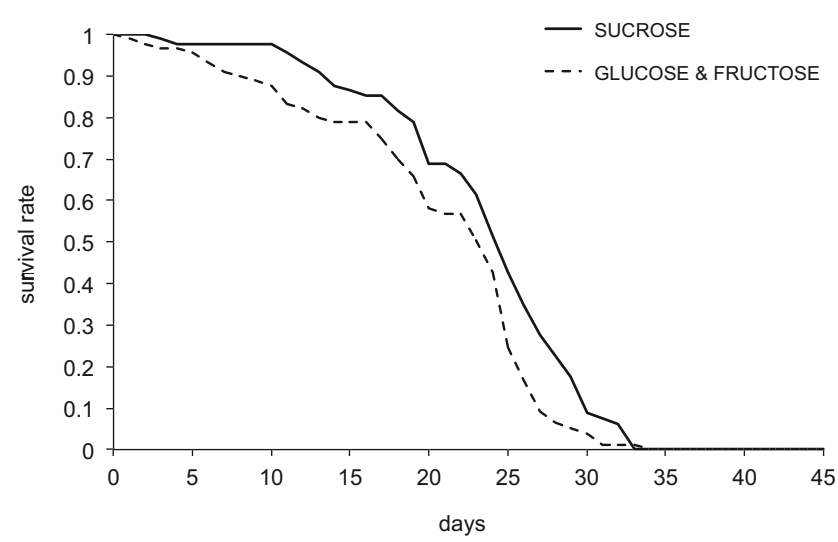

Figure 7. Survival rate of honeybees fed with a diet based on monosaccharides or disaccharides $(n=90)$.

lemon (Bartholomew 1923), and such low $\mathrm{pH}$ level can easily be reached. Since the very high concentrations of HMF that can be produced under the above mentioned conditions can be very toxic to bees (i.e., above $10,000 \mathrm{ppm}$ ), a great care should be used while making homemade syrups. This last data is consistent with the results obtained by Krainer et al. (2016) who observed that concentration of $8000 \mathrm{ppm}$ of HMF is toxic for adult honey bees.

Lemon addition is normally done to facilitate the inversion of disaccharide sugars to obtain the purportedly more digestible monosaccharides, glucose, and fructose. Indeed, hydrolysed sucrose is commonly believed to be nutritionally better for honey bees (Bailey 1966). The negative effect of lemon addition obtained here suggested to test if lemon addition is really necessary; we found that sucrose can be as effective as glucose and fructose to sustain a normal survivorship under laboratory condition. This would suggest that lemon addition may be not necessary as normally thought, possibly because bees are able to invert disaccharides themselves, thanks to $\alpha$-invertase (White 1975). However, we cannot exclude that other results could be obtained under field condition, where nutritional requirements of bees can be different. Nevertheless, our results support a careful evaluation of this aspect and, on a precautionary basis, it is suggested to beekeepers not to add the lemon juice when preparing the sugar syrup.

A further interesting result obtained in this study is the much-reduced survival observed in bees fed an acidified sugar solution after boiling for only $10 \mathrm{~min}$. This result can neither be explained solely by the negative effect of lemon addition (that it is lower), nor by the HMF concentration that could be reached in this case (that is lower than the harmful one). Indeed, our HPLC analysis showed that acidified-boiled syrups contain other substances, further than HMF, that can be related to the toxicity of these solutions, as already suggested by Bailey (1966), who found that acid-hydrolysed carbohydrates are toxic for bees due to the formation of unknown compounds in these solutions.

In conclusion, we provided convincing evidence that homemade sugar syrups can hide several possible negative side effects for bees that can impair normal survival. These negative effects can be related to the possible formation of high doses of HMF, to the acidity and to the formation of further compounds, whose identity has not been studied so far.

The golden rule of medicine "primum non nocere" (first do no harm), attributed to Hyppocrates, underlines the need of carefully considering the possible negative side effects of the treatments we may apply to sustain the health of an individual. Bees are currently exposed to a number of interacting stress factors (vanEngelsdorp et al. 2009; Hedtka et al. 2011; Dainat et al. 2012b; Nazzi et al. 2012; Nazzi and Pennacchio 2014) that may affect bee health in a complex and often unpredictable way (Di Prisco et al. 2013; Doublet et al. 2015; Nazzi and 
Pennacchio 2018). Here, we wanted to point the attention to the undesirable effects of supplementary nutrition since this has become a common practice due to the increased fragility of bees underlined above. We sincerely hope that a balanced equilibrium can be found between the need of sustain bee colonies and the risk of perturbing their normal functioning.

\section{AUTHOR CONTRIBUTIONS}

FN, DA: conceived research and designed experiments. DF, SDF, FN, DA: designed and interpreted data. DF, SDF, GO, VZ, RB, FN, DA: performed experiments and analysis. DF, FN, DA: wrote the paper and revised it.

\section{FUNDING INFORMATION}

The research leading to these results was funded by the European Union Seventh Framework Programme (FP7/2007-2013), under Grant 613960 (SMARTBEES) and by the Dipartimento di Scienze AgroAlimentari, Ambientali e Animali, University of Udine, Italy.

Effets secondaires possibles de l'alimentation complémentaire en sucre sur la santé des abeilles.

abeille domestique / hydroxyméthylfurfural / nutrition / acidité du sirop de sucre.

Mögliche Nebenwirkungen von ZuckerZusatzfütterungen auf die Bienengesundheit.

Honigbienen / Hydroxymethylfurfural / Ernährung / Zuckersyrup

\section{REFERENCES}

Amdam G.V., Fennern E., Havukainen H. (2011) Vitellogenin in honey bee behavior and lifespan. In Galizia C.G., Eisenhardt D., Giurfa M. (Eds.), Honeybee Neurobiology and Behavior: A Tribute to Randolf Menzel (pp. 17-29). Springer Sciences

Annoscia D., Zanni V., Galbraith D., Quirici A., Grozinger C., Bortolomeazzi R., Nazzi F. (2017) Elucidating the mechanisms underlying the beneficial health effects of dietary pollen on honey bees (Apis mellifera) infested by Varroa mite ectoparasites. Sci. Rep. 7, 6258

Bailey L. (1966) The effect of Acid-Hydrolysed Sucrose on Honeybees. J.Apic. Res. 5, 127-136

Barker R.J. (1971) Shouldn't a minimum food supply be specified for bee colonies rented for pollination? Glean. Bee Cult. 99, 299-315

Barker R.J., Lehner Y. (1978) Laboratory comparison of high fructose corn syrup, grape syrup, honey, and sucrose syrup as maintenance food for caged honey bees. Apidologie. 9, 111-116

Bartholomew E.T. (1923) Internal Decline of Lemons. II. Growth Rate, Water Content, and Acidity of Lemons at Different Stages of Maturity. Am. J. Bot. 10, 117-126

Benjamini Y., Hochberg Y. (1995) Controlling the false discovery rate: a practical and powerful approach to multiple testing. J. R. Stat. Soc. B (methodological) 57, 289-300

Brodschneider R., Crailsheim K. (2010) Nutrition and health in honey bees. Apidologie. 41, 278-294

Brodschneider R., Moosbeckhofer R., Crailsheim K. (2010) Surveys as a tool to record winter losses of honey bee colonies: a two year case study in Austria and Southern Tyrol. J.Apic. Res. 49, 23-30

Ceksteryte V., Racys J. (2006) The quality of syrups used for bee feeding efore winter and their suitability for bee winterin. J. Apic. Sci. 50, 1

Comparini A., Biasiolo A. (1991) Genetic characterization of Italian bee Apis mellifera ligustica Spin., versus Carnolian bee, Apis mellifera carnica Poll., by allozyme variability analysis. Biochem. Syst. Ecol. 189, 194

Dainat B., Evans J.D., Chen Y.P., Gauthier L., Neumann P. (2012a) Predictive markers of honey bee colony collapse. PLoS One 7, e32151

Dainat B., Evans J.D., Chen Y.P., Gauthier L., Neumann P. (2012b) Dead or alive: Deformed Wing Virus and Varroa destructor reduce the life span of winter honeybees. Appl. Environ. Microbiol. 78, 981-987

Di Prisco G., Cavaliere V., Annoscia D., Varricchio P., Caprio E., Nazzi F., Gargiulo G., Pennacchio F. (2013) Neonicotinoid clothianidin adversely affects insect immunity and promotes replication of a viral pathogen in honey bees. PNAS 110, 18466-18471

Dolezal A.G., Carrillo-Tripp J., Miller W.A., Bonning B.C., Toth A.L. (2016) Intensively cultivated landscape and Varroa mite infestation are associated with reduced honey bee nutritional state. PLoS One 11, e0153531

Doublet V., Labarussias M., de Miranda J.R., Moritz R.F.A., Paxton R.J. (2015) Bees under stress: sublethal doses of a neonicotinoid pesticide and pathogens interact to elevate honey bee mortality across the life cycle. Environ. Microbiol. 17, 969-983

Emsen B., Dodologlu A. (2014) Physiological characteristics of honeybee (Apis mellifera L.) colonies fed with commercial glucose. J.Anim. Vet. Adv. 13, 623-626

Free J.B., Spencer-Booth Y. (1961) Effect of feeding sugar syrup to honey-bee colonies. J. Agric. Sci. 57, 147151 
Genc F., Aksoy A. (1993) Some of the correlations between the colony development and honey production in the honeybee (Apis mellifera L.) colonies. Apis Acta 28, 33-41

Genersch E., von der Ohe W., Kaatz H., Schroeder A., Otten C., Buchler R., Berg S., Ritter W., Muhlen W., Gisder S., Meixner M., Liebig G., Rosenkranz P. (2010) The German bee monitoring project: a long term study to understand periodically high winter losses of honey bee colonies. Apidologie. 41, 332-352

Haydak M.H. (1970) Honey bee nutrition. Annu. Rev. Entomol. 15, 143-156

Hedtka K., Jensen P.M., Jensen A.B., Genersch E. (2011) Evidence for emerging parasites and pathogens influencing outbreaks of stress-related diseases like chalkbrood. J. Invertebr. Pathol. 108, 167-173

Hoštálková A., Klingelhöfer I., Morlock G.E. (2013) Comparison of an HPTLC method with the Reflectoquant assay for rapid determination of 5-hydroxymethylfurfural in honey. Anal. Bioanal. Chem. 405, 9207-9218

Jachimowicz T., El Sherbiny G. (1975) Zur Problematik der Verwendung von Invertzucker fur die Bienenfutterung. Apidologie. 6, 121-143

Krainer S., Brodschneider R., Vollmann J., Crailsheim K., Riessberger-Galle U. (2016) Effect of hydroxymethylfurfural (HMF) on mortality of artificially reared honey bee larvae (Apis mellifera carnica). Ecotoxicology. 25, 320-328

LeBlanc B.W., Eggleston G., Sammataro D., Cornett C., Dufault R., Deeby T., Cyr E.S. (2009) Formation of hydroxymethylfurfural in domestic high- fructose corn syrup and its toxicity to the honey bee (Apis mellifera). JAFC. 57, 7369-7376

Michener C.D. (2007) The bees of the world, 2nd edition. The Johns Hopkins University Press, Baltimore

Nazzi F., Milani N. (1994) A technique for reproduction of Varroa jacobsoni Oud. under laboratory conditions. Apidologie. 25 , 579-584

Nazzi F., Pennacchio F. (2014) Disentangling multiple interactions in the hive ecosystem. Trends Parasitol. 30, 12

Nazzi F., Pennacchio F. (2018) Honey bee antiviral immune barriers as Affected by multiple stress factors: a novel paradigm to interpret colony health decline and collapse. Viruses. 10, 159

Nazzi F., Brown S.P., Annoscia D., Del Piccolo F., Di Prisco G., Varricchio P., Della V.G., Cattonaro F., Caprio E., Pennacchio F. (2012) Synergistic Parasite-Pathogen Interactions Mediated by Host Immunity Can Drive the Collapse of Honeybee Colonies. PLoS Pathogen. 8, e1002735

Ptaszynska A.A., Borsuk G., Mulenko W., Olszewski K. (2013) Impact of ethanol on Nosema spp. infected bees. Med. Weter. 69, 736-740

Rinderer T.E., Baxter J.R. (1980) Honeybee hoarding of high fructose corn syrup and cane sugar syrup. Am. Bee J. 120, 817-818

Sammataro D., Weiss M. (2013) Comparison of productivity of colonies of honey bees, Apis mellifera, supplemented with sucrose or high fructose corn syrup. J. Insect Sci. 13, 1-13
Semkiw P., Skubida P. (2016) Suitability of starch syrups for winter feeding of honeybee colonies. J. Apic. Sci. 60, 2

Severson D.W., Erickson E.H. (1984) Honey bee (Hymenoptera: Apidae) colony performance in relation to supplemental carbohydrates. J. Econom. Entomol. 77, 1473-1478

Smart M., Pettis J., Rice N., Browning Z., Spivak M. (2016) Linking measures of colony and individual honey bee health to survival among apiaries exposed to varying agricultural land use. PLoS One. 11, e0152685

Smodiš Škerl M.I., Gregorc A. (2014) A preliminary laboratory study on the longevity of $A$. $m$. carnica honey bees after feeding with candies containing HMF. J. Apic. Res. 53, 422-423

Spano N., Ciulu M., Floris I., Panzanelli A., Pilo M.I., Piu P.C., Scanu R., Sanna G. (2008) Chemical characterization of a traditional honey-based Sardinian product: Abbamele. Food Chemistry. 108, 81-85

Standifer L.N., Moeller F.E., Kauffeld N.M., Herbert E.W., Shimanuki H. (1977) Supplemental Feeding of Honey Bee Colonies. U.S. Dep. Agric. Bull, 413

Thom C., Gilley D.C., Taut J. (2003) Worker piping in honey bees (Apis mellifera): the behavior of piping nectar foragers. Behav. Ecol. Sociobiol. 53 , 199-205

Tomasini D., Sampaio M.R.F., Caldas S.S., Buffon J.G., Duarte F.A., Primel E.G. (2012) Simultaneous determination of pesticides and 5-hydroxymethylfurfural in honey by the modified QuEChERS method and liquid chromatography coupled to tandem mass spectrometry. Talanta. 99, 380-386

vanEngelsdorp D., Evans J.D., Saegerman C., Mullin C., Haubruge E. (2009) Colony collapse disorder: a descriptive study. PLoS One. 4, e6481

Von der Ohe W., Schönberger H. (2002) Bienenernährung: Futtersirup im Vergleich. Bienenvater. 123, 11-15

Vrzal T., Štěrba K., Jurková M., Olšovská J. (2019) The usage of a reflectometric method for 5(hydroxymethyl)furan-2-carbaldehyde determination as a stale flavor sensor for beer. Food Packaging and Shelf Life. 19, 1-6

White J.W. (1975) Composition of honey. In Crane E. (Ed.), Honey: A comprehensive Survey (pp. 180194). Heinemann, London

Zanni V., Galbraith D.A., Annoscia D., Grozinger C.M., Nazzi F. (2017) Transcriptional signatures of parasitization and markers of colony decline in Varroainfested honey bees (Apis mellifera). Insect. Biochem. Mol. Biol. 87, 1-13

Zirbes L., Kim N.B., de Graaf D., De Meulenaer B., Reybroeck W., Haubruge E., Saegerman C. (2013) Hydroxymethylfurfural: A possible emergent cause of honey bee mortality? J. Agric. Food Chem. 61, $11865-11870$

Publisher's note Springer Nature remains neutral with regard to jurisdictional claims in published maps and institutional affiliations. 